\title{
Concerning plagiarism
}

\author{
Peter J. Strouse • Thomas L. Slovis • Guy Sebag
}

Received: 26 January 2011 / Accepted: 27 January 2011 / Published online: 22 February 2011

(C) Springer-Verlag 2011

Unfortunately, the editors of Pediatric Radiology received notification from an author that a more recent publication in our journal had been plagiarized from the author's work, published 5 years previously in a different journal. Upon rereading the recent article in question and comparing it to the preceding article, the editors determined that there were in fact large segments of text transposed verbatim or with minimal change from the earlier article. There was no credit given to the original authors, no quotation marks were used, and the original article was not even referenced. The matter is being dealt with privately by one of the editors, and the offenders have received a stern admonishment.

According to Webster's Ninth New Collegiate Dictionary, to plagiarize is "to steal or pass off (the ideas or words of another) as one's own"; to "use (a created production) without crediting the source"; or, "to commit literary theft: present as new and original an idea or product derived from an existing source" [1]. (Editor's note: please note use of direct attribution of source, quotation marks and reference to source.)

\section{P. J. Strouse ( $\varangle)$}

Section of Pediatric Radiology, C.S. Mott Children's Hospital, F3503, Department of Radiology,

University of Michigan Health System,

1500 E. Medical Center Drive,

Ann Arbor, MI 48109-0252, USA

e-mail: pstrouse@umich.edu

\section{T. L. Slovis}

Department of Pediatric Imaging,

Children's Hospital of Michigan,

Detroit, MI, USA

G. Sebag

Service d'Imagerie Pédiatrique, Hôpital Robert Debré,

Paris, France
Plagiarism is a scourge that has affected medical writing at all levels. A search via PubMed shows that major scientific journals (e.g., Science, Nature), major radiology journals (e.g., American Journal of Roentgenology) and subspecialty radiology journals (e.g., Skeletal Radiology), have all dealt with this issue (PubMed search of "plagiarism"; accessed 2:59p.m. 1/19/2011). A recent investigation highlighted plagiarism in residency applications [2]. The problem starts early.

The primary responsibility for avoiding plagiarism lies with the authors. It is the duty of the authors to produce work that is solely their own and to properly attribute material taken from other sources. This is a moral principle to which the authors attest in their copyright agreement. When in doubt, source material should be directly quoted, directly attributed in text and referenced.

Junior authors have less experience with medical writing and have less familiarity with the ethics of publishing. They need guidance. Senior authors, please take note-guidance should begin before any words appear on paper or on a computer screen. It should be stressed that words must be "your own" and words, concepts and data that are drawn from other sources need to be properly attributed and referenced. Guidance should also include careful reading and review of completed manuscripts before submission. Once again, are the words their own? Are all words, concepts and data from other sources properly attributed, quoted and referenced? The senior author must critically review the manuscript for sections that might not be the junior author's own words. Directly compare the reference material to the manuscript. Senior authors are every bit as much responsible for plagiarized material as the junior author(s) whom they mentor. Over the years, we have had senior authors complain about improper submission by junior staff. In most instances, the senior authors have not 
carried out their oversight responsibilities and merely signed the conflict of interest form!

True or not, there is a sense that plagiarism is a greater problem in manuscripts submitted from outside of the traditional North American and European catchment of most English language medical journals. This might be a result of inexperience, lack of familiarity with the ethics of publication, intense pressure to publish and many other factors. Unfortunately, we have seen some examples in manuscripts submitted to Pediatric Radiology from all over the world. These have been detected by astute reviewers.

Reviewers play an important role in identifying plagiarism. The integrity of the manuscript is within their purview. Careful reviewers will pull references, perform literature searches, and read and compare. They will critically evaluate suspicious text and bring it to the attention of the editors for more detailed review. Nonetheless, it is erroneous to assume that reviewers can feasibly detect more than a small fraction of plagiarized work.

It is likewise impracticable to assume that editors will detect but a small fraction of plagiarized work. The editors are obliged to carefully investigate possible instances of plagiarism, both within submitted material and within articles that have already been published. Is it plagiarism? How egregious is the offense? What should the consequences be? Like radiology itself, such questions are not always black and white and each case merits individualized attention and response. Computer programs have been developed to detect plagiarized text by comparison to the extant body of medical literature. These programs bear expense and labor, and their efficacy is unproven. However, this is a potential means for editorial offices and publishing companies to identify and minimize the scourge of plagiarism. We will be trialing one of these programs for review of all accepted manuscripts beginning this year.

In the end, the moral and ethical responsibility chiefly resides with the author(s). While reviewers, editors and publishers can try to detect plagiarism, it is simply best that it not occur in the first place. Fortunately, plagiarism appears to be a rare occurrence in Pediatric Radiology. Nonetheless, when it occurs it is sad, embarrassing, uncomfortable and unfortunate. We are disappointed. We apologize to the authors whose work was plagiarized in this instance. There is no acceptable excuse.

Acknowledgement The authors thank Michael A. DiPietro, MD, for his editorial assistance.

\section{References}

1. Mish FC (ed) (1991) Webster's ninth new collegiate dictionary. Merriam-Webster, Springfield, p 898

2. Segal S, Gelfand BJ, Hurwitz S et al (2010) Plagiarism in residency application essays. Ann Intern Med 2010:112-120 